\title{
Recovery from blocking achieved by extinguishing the blocking CS
}

\author{
AARON P. BLAISDELL \\ State University of New York, Binghamton, New York \\ LISA M. GUNTHER \\ Greensboro College, Greensboro, North Carolina \\ and \\ RALPH R. MILLER \\ State University of New York, Binghamton, New York
}

\begin{abstract}
Extinction-induced attenuation of single-phase and two-phase blocking was examined with rats in a conditioned lick-suppression task. In Experiment 1, which compared the effectiveness of single- and two-phase blocking, it was found that single-phase blocking was facilitated by the initiation of training with an A-US trial rather than an AX-US trial. Single-phase (but not two-phase) blocking was attenuated as a result of 200 extinction trials with the blocking stimulus (Experiment 2). Experiment 3 revealed recovery from two-phase blocking after 800 extinction trials with the blocking stimulus. Recovery from both types of blocking was specific to the blocked CS trained in compound with the extinguished stimulus (Experiment 4). This is the first article to report that the blocking deficit can be reversed by extinguishing the blocking stimulus. These results are discussed in light of acquisition models (i.e., retrospective revaluation) and expression models (i.e., the comparator hypothesis).
\end{abstract}

Kamin (1968) reported reduced conditioned responding to a cue $(\mathrm{X})$ that was paired with an unconditioned stimulus (US) in the presence of a second cue (A) as a result of A's having been previously paired with the US. This phenomenon, called "blocking," has been traditionally interpreted as an acquisition failure, in which the prior training with $\mathrm{A}$ prevents $\mathrm{X}$ from acquiring appreciable associative strength during training (e.g., Kamin, 1968; Mackintosh, 1975; Pearce, 1987; Pearce \& Hall, 1980; Rescorla \& Wagner, 1972). According to acquisitiondeficit models, the blocked stimulus is prevented from forming a strong association with the US; thus, because the subject has presumably not acquired the critical CS-US association, blocking should be irreversible in the absence of further training with the blocked stimulus.

However, evidence for an expression-failure (e.g., retrieval-failure) interpretation of cue-competition effects (of which blocking is one example) has appeared over the last 15 years. Most reports supporting an expressiondeficit view demonstrate reversal of cue-competition effects in the absence of further training with the target con-

Support for this research was provided by NIMH Grant 33881. We thank Adam Bristol, Daniel C. Burger, James C. Denniston, Martha C. Escobar, Haney Mallemat, Hernan Savastano, and Russell Wishtart for comments on a preliminary draft of this manuscript. Thanks are also extended to James Esposito and Barry Friedman for assistance with the collection of data. Requests for reprints should be addressed to R. R. Miller, Department of Psychology, State University of New York, Binghamton, NY 13902-6000 (e-mail: rmiller@binghamton.edu).

Note-Vincent M. LoLordo served as the action editor for this manuscript. ditioned stimulus (CS). Currently, there are at least three established ways of reversing cue-competition effects: delayed testing (i.e., spontaneous recovery), posttraining reminder treatments, and posttraining extinction of the competing cue. For example, these procedures have been applied to another form of cue competition known as overshadowing, in which one (and sometimes both) of two simultaneously trained CSs is impaired in its control of conditioned responding relative to that cue when it is trained without the second CS (Pavlov, 1927). In accord with expression-failure models, the overshadowing deficit has been reversed with delayed testing (Kraemer, Lariviere, \& Spear, 1988), "reminder" treatments consisting of presentation of the target CS alone (Kasprow, Cacheiro, Balaz, \& Miller, 1982), and massive posttraining extinction of the overshadowing CS (Kaufman \& Bolles, 1981; Matzel, Schachtman, \& Miller, 1985; Matzel, Shuster, \& Miller, 1987). Similar results have been obtained with a form of cue competition called the relative stimulus-validity effect (Cole, Barnet, \& Miller, 1995; Cole, Denniston, \& Miller, 1996; Cole, Gunther, \& Miller, 1997).

This report concerns recovery from blocking. Responding to a blocked CS has been restored through delayed testing (i.e., spontaneous recovery; Batsell, 1997) and reminder treatments (Balaz, Gutsin, Cacheiro, \& Miller, 1982; Schachtman, Gee, Kasprow, \& Miller, 1983). However, several studies in our laboratory have failed to obtain recovery from blocking through extinction of the blocking stimulus (Miller, Schachtman, \& Matzel, 1988). The failure to obtain recovery from blocking 
through posttraining extinction of the blocking CS has been a notable failure of expression-deficit explanations of blocking. The rationale for expecting posttraining extinction of the blocking stimulus to affect recovery is provided by the comparator hypothesis, which is a rule for the expression (as opposed to acquisition) of acquired associations (Miller \& Matzel, 1988; Miller \& Schachtman, 1985). The comparator hypothesis explains cuecompetition effects as follows. During training, associations are formed (as a result of contiguity) between (1) the target CS and the US, (2) the target CS and any other salient stimulus present during CS training (i.e., "comparator stimulus"), and (3) the comparator stimulus and the US. The comparator hypothesis states that excitatory responding to a CS will be both directly related to the strength of the CS-US association (i.e., 1) and inversely related to the product of the CS-comparator stimulus association (i.e., 2) and the comparator stimulus-US association (i.e., 3) at the time of testing. Therefore, posttraining nonreinforced exposures to a CS's comparator stimulus should decrease the value of the comparator stimulus-US association and perhaps the CS-comparator stimulus association, thereby enhancing excitatory responding to that $\mathrm{CS}$ by allowing expression of the $\mathrm{CS}-$ US association.

In most instances, this prediction has been substantiated, provided sufficiently massive posttraining extinction of the comparator stimulus is given. As previously mentioned, recovery as a result of posttraining extinction of the competing stimulus has been demonstrated for types of cue competition other than blocking (Cole et al., 1995; Dickinson \& Charnock, 1985; Kaufman \& Bolles, 1981; Matzel et al., 1985; Matzel, Shuster, \& Miller, 1987; Miller, Barnet, \& Grahame, 1992). When the comparator hypothesis is applied to the blocking procedure, the blocking stimulus (A) is presumably the comparator stimulus for the blocked target stimulus $(\mathrm{X})$ because $A$ is the most salient cue, other than $X$ and the US, that is present during conditioning of $X$. A hint that recovery from blocking could result from extinction of the blocking stimulus comes from the fact that the USpreexposure effect (which is frequently regarded as a result of blocking by the context) can be attenuated by posttraining extinction of the training context (Barnet, Grahame, \& Miller, 1993; Matzel, Brown, \& Miller, 1987).

The repeated failures to obtain recovery from blocking by posttraining extinction of the blocking stimulus (Miller et al., 1988) are a challenge to the comparatorhypothesis view of cue competition. There are at least two possible reasons for the failure to observe recovery from blocking after extinguishing the blocking stimulus. One possible reason arises from the phasic nature of conventional blocking paradigms (i.e., A-US in Phase 1 and AX-US in Phase 2). Cue-competition effects for which posttraining extinction of comparator stimuli has been found to attenuate the deficits in responding due to cue competition (e.g., overshadowing and the relative stimulus-validity effect) involve procedures in which all rel- evant stimulus conditions are presented within a single phase of training. In the single-phase blocking procedure, there are few or no trials in which $\mathrm{A}$ alone is paired with the US before the first AX-US trial, and therefore $A$ and $X$ start out at the beginning of training with similar response potentials (presumably zero) on the first AX-US trial. In contrast, in the conventional two-phase blocking procedure, prior to the first compound trial A has already acquired much greater control of behavior than $\mathrm{X}$ because in that procedure the comparator stimulus is presented with the US many times prior to the target CS. Toward assessing this potential factor, in the present research we examined recovery of responding to the blocked $\mathrm{CS}$ as a consequence of the posttraining extinction of $\mathrm{A}$ in both conventional two-phase blocking and single-phase blocking (i.e., interspersed A-US and AXUS trials).

A second possible reason for the failure to observe recovery of responding to the blocked CS after extinguishing the blocking stimulus is the large number of A-US trials relative to AX-US trials. Notably, even recovery from other types of single-phase cue competition, such as overshadowing and the effect of low relative stimulus validity produced by extinction of comparator stimuli, requires a surprisingly large number of extinction trials. In fact, this number of extinction trials is far more than is required to eliminate direct conditioned responding to the comparator stimulus. For example, Miller et al. (1992) administered $216 \mathrm{~A}$ - trials in order to obtain recovery from overshadowing after having given only $4 \mathrm{AX}$-US overshadowing training trials (preliminary studies in that research found that 48 or fewer A - extinction trials did not yield recovery). Perhaps a ratio rule can be used as a heuristic in efforts to alleviate blocking. If about 200 extinction of A trials are needed to recover responding to an overshadowed stimulus after 4 trials of overshadowing training (4 AX-US trials, in which 4 A-US pairings are embedded), which is a 50 to 1 ratio, then approximately $800 \mathrm{~A}$ - extinction trials may be necessary to produce recovery from blocking after the 16 A-US trials of our usual blocking preparation (12 A-US followed by 4 AX-US trials). Experiments 2 and 3 tested this prediction by observing the effects of 200 and 800 extinction-of-A trials on the response deficit commonly observed following two-phase blocking. (For further discussion of the large number of $A-$ trials necessary to alter responding to the target stimulus, see Williams \& Docking, 1995.)

\section{EXPERIMENT 1}

In preparation for Experiments 2-4, in which we examined recovery from blocking, Experiment 1 was designed to simply demonstrate blocking with both the conventional two-phase procedure and the single-phase procedure, and to determine some of the conditions that facilitate single-phase blocking (see Table 1) because single-phase blocking has not been investigated as thor- 
Table 1

Design: Experiment 1

\begin{tabular}{lllc}
\hline \multicolumn{1}{c}{ Group } & \multicolumn{1}{c}{$\begin{array}{c}\text { Initial } \\
\text { Conditioning } \\
\text { (First Day) }\end{array}$} & $\begin{array}{c}\text { Subsequent } \\
\text { Conditioning }\end{array}$ & Test \\
\hline Single-Ph B & $2 \mathrm{~A}+$, then $\mathrm{AX}+$, then $\mathrm{A}+$ & $9 \mathrm{~A}+/ 3 \mathrm{AX}+$ & $\mathrm{X}$ \\
Single-Ph C & $2 \mathrm{D}+$, then $\mathrm{AX}+$, then $\mathrm{D}^{+}$ & $9 \mathrm{D}+/ 3 \mathrm{AX}+$ & $\mathrm{X}$ \\
Two-Ph B & $4 \mathrm{~A}+$ & $8 \mathrm{~A}+$, then 4AX+ & $\mathrm{X}$ \\
Two-Ph C & $4 \mathrm{D}+$ & $8 \mathrm{D}+$, then 4AX+ & $\mathrm{X}$ \\
Necessary B & $1 \mathrm{AX}+$, then 3A+ & $9 \mathrm{~A}+/ 3 \mathrm{AX}+$ & $\mathrm{X}$ \\
Necessary C & $1 \mathrm{AX}+$, then 3D+ & $9 \mathrm{D}+/ 3 \mathrm{AX}+$ & $\mathrm{X}$ \\
Sufficient & $2 \mathrm{~A}+$, then AX+, then $\mathrm{D}+$ & $9 \mathrm{D}+/ 3 \mathrm{AX}+$ & $\mathrm{X}$ \\
\hline
\end{tabular}

Note $-\mathrm{B}^{*}=$ blocking treatment; $\mathrm{C}=$ control for blocking; $\mathrm{A}$ and $\mathrm{D}$ were tone and noise, counterbalanced within groups; $\mathrm{X}$ was a click train; + represents the footshock US. The slash $(/)$ indicates that treatments on either side of the slash were interspersed. Numbers indicate the total number of each type of trial.

oughly as two-phase blocking. Two treatment conditions, single-phase blocking and two-phase blocking, were used to compare the amount of blocking that results from each procedure. Blocking (B) subjects received A-US trials, whereas control $(C)$ subjects were administered D-US trials, with all subjects also receiving AX-US trials. The order in which trials were presented was also varied between groups within the single-phase condition. All subjects in the single-phase condition received three elemental trials (A-US) and one compound trial (AX-US) during each session. In the first session, Groups Singlephase $(\mathrm{Ph}) \mathrm{B}$ and Single-Ph C first received two A-US or D-US trials, respectively, followed by one AX-US trial, which in turn was followed by one more A-US or D-US trial, respectively. Groups Necessary B and Necessary $C$ received one $A X$-US trial first, followed by three A-US or D-US trials, respectively. Groups Necessary $B$ and Necessary $C$ were included to assess whether the first two A-US trials of Group Single-Ph B were necessary to obtain a deficit in responding to $\mathrm{X}$. If two A-US trials, prior to any AX-US trials, are necessary to produce blocking of $X$ by $A$, then Group Necessary B, which received an AX-US trial prior to any A-US trials, should not exhibit a deficit in responding to $X$. On the first day of blocking training, Group Sufficient received two A-US trials, followed by one AX-US trial followed by one D-US trial. During all subsequent blocking training sessions, Group Sufficient received one D-US trial, followed by one AX-US trial, followed by two more D-US trials. Thus, Group Sufficient received only two A-US trials, in total, which were administered prior to any AX-US trials. The purpose of this manipulation was to assess whether the initial two A-US trials received by subjects in Group Single-Ph B were sufficient to produce blocking of $\mathrm{X}$ by $\mathrm{A}$. If so, less conditioned responding to $X$ (i.e., blocking) should be observed in Group Sufficient (which initially received two A-US trials) than in Group Single- $\mathrm{Ph} \mathrm{C}$ (which initially received two D-US trials). We suspected that two initial A-US trials would not alone suffice to attenuate responding to $X$ and that the subsequent $\mathrm{A}$-US trials throughout training would be needed to produce single-phase blocking. Thus, we expected strong conditioned responding in both Group Sufficient and Group Single-Ph C. Finally, Groups Two-Ph B and Two-Ph $\mathrm{C}$ served as standard two-phase blocking experimental and control groups, respectively, by which to assess the amount of single-phase blocking relative to twophase blocking. Throughout this research, the blocking CS was a stimulus that we judged to be somewhat less salient than the blocked CS, thereby minimizing overshadowing of the blocked CS which, in any case, should have been uniform across groups.

\section{Method}

\section{Subjects}

Twenty-one male (280-400 g) and 21 female (190-260 g) Sprague-Dawley-descended rats, bred in our colony from Holtzman stock, served as subjects. The animals were randomly assigned to one of seven groups ( $n s=6)$. The animals were individually housed in wire-mesh cages in a vivarium maintained on a 16:8-h light:dark cycle. All experimental manipulations occurred approximately midway through the light portion of the cycle. Food was freely available in the home cage. A progressive water-deprivation schedule was imposed over the week prior to the initiation of the experiment, until water availability was limited to $30 \mathrm{~min}$ per day. Water was provided approximately $1 \mathrm{~h}$ after any treatment scheduled for that day. All animals were handled three times per week for $30 \mathrm{sec}$ from weaning until the beginning of the study.

\section{Apparatus}

Twelve identical chambers, each measuring $30 \times 25 \times 32 \mathrm{~cm}$ $(1 \times w \times h)$, were used. The walls of each chamber were made of Plexiglas, and the floor was constructed of $0.5-\mathrm{cm}$-diameter rods, spaced $2 \mathrm{~cm}$ center-to-center and connected by NE- 2 neon bulbs that allowed a $1.0-\mathrm{mA}$ constant-current footshock to be delivered by means of a high-voltage ac circuit in series with a $1.0-\mathrm{MW}$ resistor. Each chamber was housed in an environmental isolation chest, which was dimly illuminated by a houselight (No. 1820 incandescent bulb) mounted on the ceiling of the experimental chamber. Each chamber was equipped with a water-filled lick tube (opening $=0.3 \mathrm{~cm}$ in diameter) that extended about $1 \mathrm{~cm}$ from the rear of a cylindrical niche, $4.5 \mathrm{~cm}$ in diameter, that was left-right centered on one wall, with its axis perpendicular to the wall and positioned $4 \mathrm{~cm}$ above the grid floor. An infrared photobeam was projected horizontally across the niche, $1 \mathrm{~cm}$ in front of the lick tube. To drink from the tube, the subjects had to insert their heads into the niche, thereby breaking the horizontal infrared photobeam. Thus, the amount of time the photobeam was disrupted could be monitored; this served as our dependent measure. A 45-W speaker mounted on the interior back side of each environmental chest could deliver a high-frequency complex tone (T; 3000 and $3200 \mathrm{~Hz}$ ) $6 \mathrm{~dB}(\mathrm{C}) \mathrm{SPL}$ above background. A second $45-\mathrm{W}$ speaker mounted on the ceiling of the experimental chamber was used to deliver a click (C) stimulus $(6 / \mathrm{sec}) 8 \mathrm{~dB}(\mathrm{C})$ above background. A third 45-W speaker mounted on the side wall of the chamber was used to deliver a white noise $(\mathrm{N})$ stimulus $6 \mathrm{~dB}(\mathrm{C})$ above background. The tone and white noise, counterbalanced. within groups, served as A and D. The clicks always served as X. Ventilation fans in each enclosure provided a constant $76-\mathrm{dB}(\mathrm{C})$ background noise. All CSs during training were $10 \mathrm{sec}$ in duration. The 1.0-mA footshock US was $0.5 \mathrm{sec}$ in duration and occurred immediately upon termination of the CS presented on that trial. 


\section{Procedure}

Table 1 summarizes the critical aspects of the training procedure. All training and testing occurred in the same chamber for any given subject.

Acclimation. On Day 1, all subjects received 30 min of acclimation to the experimental chambers with the lick tubes available. This served to establish and stabilize baseline licking behavior and acclimate the animals to the experimental context.

Blocking training. On Days 2-5, subjects received four pseudorandomly distributed trials with an average intertrial interval of $12 \mathrm{~min}$ in each daily 60 -min session, with the lick tube absent. On Day 2, subjects in Groups Single- $\mathrm{Ph} B$ and Single- $\mathrm{Ph} \mathrm{C}$ received two trials of A-US or D-US, respectively, followed by one trial of AX-US, followed by a trial of A-US or D-US, respectively. Subjects in Groups Necessary B and Necessary C received one AX-US trial followed by three trials of A-US or D-US, respectively. Subjects in Group Sufficient received two trials of A-US, followed by one AX-US trial, followed by one D-US trial. Subjects in Groups Two-Ph B and Two-Ph C received four trials of A-US or D-US, respectively.

On Days 3 and 4, subjects in Groups Single-Ph B and Necessary $B$ received one A-US trial, followed by one AX-US trial, followed by two A-US trials per daily session. Subjects in Groups Single-Ph C, Necessary C, and Sufficient received one D-US trial, followed by one AX-US trial, followed by two D-US trials per daily session. Subjects in Groups Two-Ph B and Two- $\mathrm{Ph} C$ received four trials of A-US and D-US trials per daily session, respectively.

On Day 5, subjects in Groups Single-Ph B and Necessary B again received one A-US trial, followed by one $\mathrm{AX}$-US trial, followed by two A-US trials. Subjects in Groups Single-Ph C, Necessary C, and Sufficient again received one D-US trial, followed by one AX-US trial, followed by two D US trials. Subjects in Groups Two-Ph B and Two-Ph $\mathrm{C}$ received four AX-US trials.

Reacclimation. On Days 6 and 7, lick tubes were reinstalled and subjects were allowed to drink for each daily 1 -h session. These sessions did not include any nominal stimulus presentations and served to restabilize baseline drinking.

Testing. On Day 8, all subjects were tested for conditioned lick suppression to X. Stimulus $\mathrm{X}$ was presented upon completion of an initial 5 cumulative seconds of drinking upon placement in the chamber (as measured by the total amount of time the infrared beam was disrupted). Thus, all subjects were drinking at CS onset. Times to complete the first 5 cumulative seconds of licking (i.e., prior to CS onset) and times to complete an additional 5 cumulative seconds of licking in the presence of the test $C S$ were recorded. The latter time was our principal dependent variable. A 15-min ceiling was imposed on subjects for completing 5 cumulative seconds of drinking in the presence of $X$.

In all of the experiments reported, suppression data were transformed to $\log$ (base 10) scores to better meet the assumptions of parametric statistics. Additionally, following the convention of our laboratory, subjects that took over $60 \mathrm{sec}$ to complete their first 5 cumulative seconds of licking (i.e., prior to CS onset) were scheduled to be eliminated from the study because of their showing unusually great fear of the test context. No subjects from this experiment had to be eliminated based on this criterion. An alpha level of .05 was adopted for all tests of statistical significance.

\section{Results and Discussion}

The central observation from Experiment 1 was that CS A blocked conditioned suppression to CS X in Groups Two-Ph B and Single-Ph B. Furthermore, in the singlephase condition, the first two A-US trials prior to any AX-US trials were necessary, though not sufficient, to produce a blocking effect (Group Single-Ph B vs. Groups
Necessary B and Sufficient, respectively). These outcomes are depicted in Figure 1.

A one-way analysis of variance (ANOVA) conducted on pre-CS times to complete 5 cumulative seconds of licking revealed no significant group differences in baseline drinking behavior in this experiment (or in any of the subsequently described experiments; $F \mathrm{~s}<1.0$ ). This indicates that the groups did not significantly differ with respect to fear of the test context.

A similar ANOVA conducted on times to complete 5 cumulative seconds of licking in the presence of $\mathrm{X}$ revealed a treatment effect $[F(6,35)=4.98, p<.001]$. Planned comparisons were conducted using the overall error term from the ANOVA. Group Two-Ph B suppressed less than Group Two-Ph $\mathrm{C}[F(1,35)=9.75, p<$ $.01]$; thus two-phase blocking was demonstrated. Group Single-Ph B suppressed less than Group Single-Ph C $[F(1,35)=5.29, p<.05]$, thus documenting single-phase blocking. Group Necessary B did not suppress less than Group Necessary C $[F(1,35)<1.0, p>.85]$, indicating that beginning training with a single $\mathrm{AX}$-US trial on the first day of blocking treatment prevented A from attenuating responding to $X$. The lack of a difference between Groups Single-Ph C and Sufficient $[F(1,35)=1.22, p>$ $.25]$ suggests (to the extent that a null finding can) that the initial two A-US trials on the first day of blocking treatment failed to produce single-phase blocking without further A-US training. The latter two comparisons (between Groups Necessary B and Necessary C and between Groups Single-Ph C and Sufficient) collectively demonstrate that the initial two A-US trials on the first day of single-phase blocking treatment were necessary but not sufficient to support single-phase blocking of $\mathrm{X}$ by A. Subsequent A-US alone trials interspersed with the AX-US trials were necessary to produce the effect.

In conclusion, Experiment 1 demonstrated both twophase and single-phase blocking with our parameters and determined that both the initial few A-US trials prior to any AX-US trial and the subsequent A-US trials intermingled with $\mathrm{AX}-\mathrm{US}$ trials are required to produce single-phase blocking comparable in magnitude to that of two-phase blocking.

\section{EXPERIMENT 2}

In Experiment 1, we established an effective procedure for producing both single-phase and two-phase blocking. Thus, our aim in Experiment 2 was to look for recovery of responding to the blocked $\mathrm{CS}$ after single-phase and two-phase blocking achieved by massive posttraining extinction of the blocking stimulus. To reiterate, one possible reason why our laboratory has previously not been able to obtain recovery from blocking by posttraining extinction of the blocking stimulus (A) is that, in a typical two-phase blocking experiment, many A-US trials ( 12 in our procedure) occur prior to any compound $\mathrm{AX}$-US trials. Under these conditions, pretraining with Stimulus A may maximally prevent $\mathrm{X}$ from acquiring what we call 


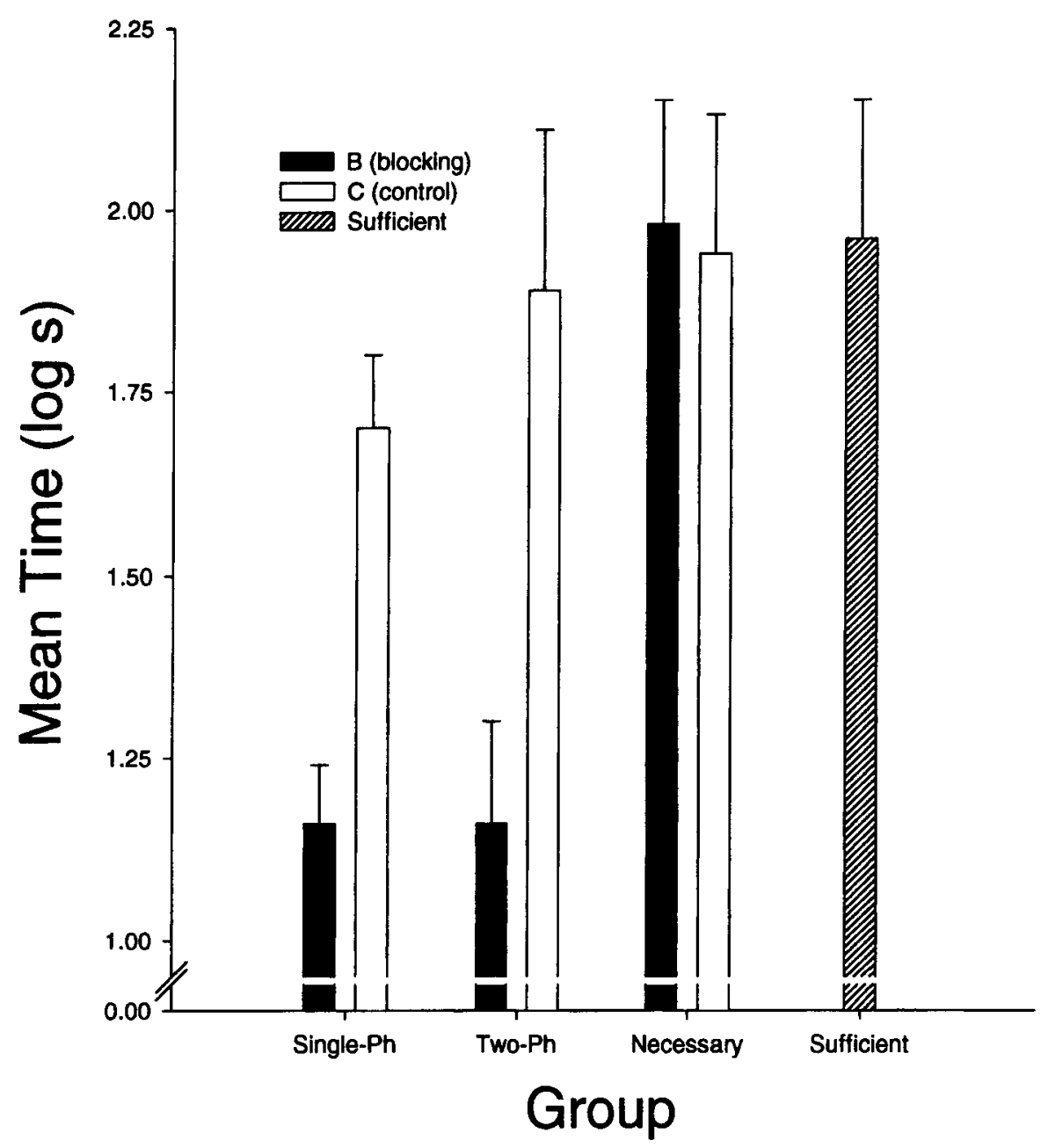

Figure 1. Experiment 1: Mean times to lick for 5 cumulative seconds in the presence of $X$ (the blocked stimulus). Error bars represent standard errors of means.

biological significance. "Biological significance" here denotes a stimulus's maximal response potential (including potentials below the threshold for overt responding) across the stimulus' complete training history. Biological significance of a CS is assumed to increase monotonically with the number of CS-US pairings, but at a slower rate when the target cue's comparator stimulus is highly excitatory than when the comparator stimulus is less excitatory. In contrast, the single-phase procedure that produced blocking in Experiment 1 administered only two A-US trials prior to the first AX-US trial. Hence, in the single-phase procedure, it is likely that, because of the lower strength of the A-US association at the time of this AX-US trial, $\mathrm{X}$ acquired more biological significance (but still below the threshold for responding, as evidenced by the deficit in responding to $X$ ) on this first AX-US trial than it did in the two-phase condition. Denniston, Miller, and Matute (1996) and Miller and Matute (1996) have demonstrated that stimuli are resistant to cue competition (e.g., blocking) in direct relationship to their amount of biological significance. Thus, even the approximately 200 extinction trials with A that were found to reverse overshadowing and the relative validity effect may not suffice to overcome the difference in biological significance between $\mathrm{A}$ and $\mathrm{X}$ established during two-phase blocking treatment. However, if the A-US and AX-US trials occur interspersed within the same session throughout training (i.e., the single-phase blocking procedure), $X$ likely acquires a moderate amount of biological significance early in training. Thus, a moderate amount of biological significance accrued by $\mathrm{X}$ after single-phase blocking treatment may allow 200 extinction trials with $\mathrm{A}$ to recover responding to $\mathrm{X}$. This hypothesis suggests that more responding to $\mathrm{X}$ should have been seen after single-phase blocking than after two-phase blocking in Experiment 1. Unfortunately, evaluation of this hypothesis by comparing Groups Single-Ph B and Two-Ph B of Experiment 1 is not possible because the 
response potential of both of these groups was probably below the threshold for producing lick suppression (i.e., a floor effect).

Within the extinction phase of Experiment 2, half of the subjects received 200 nonreinforced presentations of A (extinction treatment) after receiving either a singleor a two-phase blocking treatment; the rest of the subjects received an equivalent amount of handling and context experience, but without the extinction manipulation. If the single-phase blocking procedure results in a smaller difference in associative strength between the A and $\mathrm{X}$ stimuli relative to two-phase blocking, then we would expect to observe recovery from blocking in the single-phase condition, but less or no recovery in the two-phase condition.

\section{Method \\ Subjects and Apparatus}

Twenty-four male $(330-460 \mathrm{~g})$ and 24 female (245-300 g) Sprague-Dawley rats, bred in our colony from Holtzman stock, served as subjects. The animals were randomly assigned to one of eight groups ( $n s=6)$. The animals were housed and maintained as in Experiment 1. The apparatus and stimuli were identical to those used in Experiment 1, except where indicated.

Two contexts were used, Context 1 for blocking treatment and Context 2 for extinction treatment and testing. Context 1 was identical to that described in Experiment 1. Context 2 was created by using a different instance of Context 1 for each subject, turning off the houselight, and providing an odor cue (two drops of $98 \%$ methyl salicylate on a wooden block placed inside the environmental enclosure). A second context was used for extinction of A because preliminary research had suggested that massive exposure to the training context alone tended to enhance the effective associative value of A. We wanted the control groups to be equated with the experimental groups for exposure to each context and yet we did not want that context exposure to have any influence on test trial responding to $X$ by the control groups. Because prior research had found recovery effects to be context specific (Gunther, Denniston, \& Miller, 1998), testing was done in the context used to extinguish the comparator stimulus.

\section{Procedure}

The critical aspects of Experiment 2 are depicted in Table 2. Acclimation and blocking treatments for the single-phase and two-

Table 2

Design: Experiment 2

\begin{tabular}{llll}
\hline \multicolumn{1}{c}{ Group } & \multicolumn{1}{c}{$\begin{array}{c}\text { Phase } 1 \\
\text { Conditioning }\end{array}$} & $\begin{array}{c}\text { Phase } 2 \\
\text { Extinction }\end{array}$ & Test \\
\hline Single-Ph B.N & $12 \mathrm{~A}+/ 4 \mathrm{AX}+$ & context only & $\mathrm{X}, \mathrm{A}$ \\
Single-Ph C.N & $12 \mathrm{D}+/ 4 \mathrm{AX}+$ & context only & $\mathrm{X}, \mathrm{A}$ \\
Two-Ph B.N & $12 \mathrm{~A}+$, then $4 \mathrm{AX}+$ & context only & $\mathrm{X}, \mathrm{A}$ \\
Two-Ph C.N & $12 \mathrm{D}+$, then $4 \mathrm{AX}+$ & context only & $\mathrm{X}, \mathrm{A}$ \\
Single-Ph B.E & $12 \mathrm{~A}+/ 4 \mathrm{AX}+$ & $200 \mathrm{~A}-$ & $\mathrm{X}, \mathrm{A}$ \\
Single-Ph C.E & $12 \mathrm{D}+/ 4 \mathrm{AX}+$ & $200 \mathrm{~A}-$ & $\mathrm{X}, \mathrm{A}$ \\
Two-Ph B.E & $12 \mathrm{~A}+$, then $4 \mathrm{AX}+$ & $200 \mathrm{~A}-$ & $\mathrm{X}, \mathrm{A}$ \\
Two-Ph C.E & $12 \mathrm{D}+$, then $4 \mathrm{AX}+$ & $200 \mathrm{~A}-$ & $\mathrm{X}, \mathrm{A}$ \\
\hline
\end{tabular}

Note $-\mathrm{B}=$ blocking treatment $\mathrm{C}=$ control for blocking; $\mathrm{E}=$ extinction treatment; $N=$ no extinction; $A$ and $D$ were tone and noise, counterbalanced within groups; $X$ was a click train; + represents the footshock US; - represents the absence of footshock. The slash (/) indicates that treatments on either side of the slash were interspersed. Numbers indicate the total number of each type of trial. phase conditions of Experiment 2 were identical to those received by the single-phase and two-phase conditions, respectively, of Experiment 1 . All subjects in the single-phase condition received three elemental trials (A-US) and one compound trial (AX-US) during each of four training sessions. In the first training session, Groups Single-Ph B.N and Single-Ph B.E received two A-US trials, followed by one AX-US trial, followed by another A-US trial. Groups Single-Ph C.N and Single-Ph C.E received two D-US trials, followed by one AX-US trial, followed by one more D-US trial. In the second through fourth training sessions, Groups Single-Ph B.N and Single-Ph B.E received one A-US trial, followed by one AX-US trial, followed by two more A-US trials. Groups Single-Ph C.N and Single- $\mathrm{Ph}$ C.E received one D-US trial, followed by one AX-US trial, followed by two more D-US trials. During the first three daily sessions, Groups Two-Ph B.N and Two-Ph B.E received only A-US trials and Groups Two-Ph C.N and Two-Ph C.E received only D-US trials. In the fourth training session, these four groups received only AX-US trials.

Extinction. On Days 6-13, subjects in the extinction groups (Condition E: Groups Single-Ph B.E, Single-Ph C.E, Two-Ph B.E, and Two-Ph C.E) received $25 \mathrm{~A}$ - trials (i.e., extinction treatment) with an intertrial interval of $4 \pm 2$ min during each daily 2 -h session in Context 2 , for a total of 200 posttraining $A$ - trials. The duration of each presentation of A was $10 \mathrm{sec}$, the same duration that was used in training. The lick tubes were available during these sessions. Subjects in the no-extinction condition (i.e., Condition N: Groups Single-Ph B.N, Single-Ph C.N, Two-Ph B.N, and Two-Ph C.N) received equivalent exposure to Context 2 with no nominal stimulus presentations.

Reacclimation. On Days 14 and 15, the subjects were given access to the lick tubes in Context 2 during daily $1-\mathrm{h}$ sessions which served to restabilize baseline levels of drinking. There were no nominal stimulus presentations during these sessions.

Testing. On Day 16, all subjects were tested for conditioned lick suppression in response to Stimulus X, as in Experiment 1, except that Stimulus X remained on for an entire 15-min session in Context 2. Maintaining $X$ for a uniform 15 min ensured that data collected on Day 17 were not differentially influenced across groups by differing treatment on Day 16. On Day 17, all subjects were tested for suppression to A by presenting Stimulus A after the first 5 cumulative seconds of licking behavior, with a 15 -min ceiling. We always tested first on $X$ because responding to $X$ was of primary interest. Testing first on $A$ would have required presenting $A$ for $15 \mathrm{~min}$, which might have influenced subsequent responding to $\mathrm{X}$. Obviously, 15 min of exposure to X on Day 16 might have influenced responding to A on Day 17 in our current procedure, but we were less interested in suppression to A than in suppression to $X$. No animal took longer than $60 \mathrm{sec}$ to complete the first $5 \mathrm{cu}-$ mulative seconds of drinking (i.e., prior to onset of the test stimulus) on either test day.

\section{Results and Discussion}

The single-phase and two-phase blocking effects of Experiment 1 were successfully replicated. Posttraining extinction of the blocking stimulus (A) resulted in conditioned suppression to $\mathrm{X}$ in the single-phase condition but not in the two-phase condition. These outcomes are illustrated in Figure 2.

A $2 \times 2 \times 2$ ANOVA (single-phase vs. two-phase; blocking vs. control; extinction [E] vs. no extinction $[\mathrm{N}]$ ) was conducted on the suppression scores to $X$. This revealed main effects of single-phase versus two-phase blocking $[F(1,40)=7.75, p<.01]$ and blocking versus control $[F(1,40)=21.09, p<.0001]$, a two-way inter- 


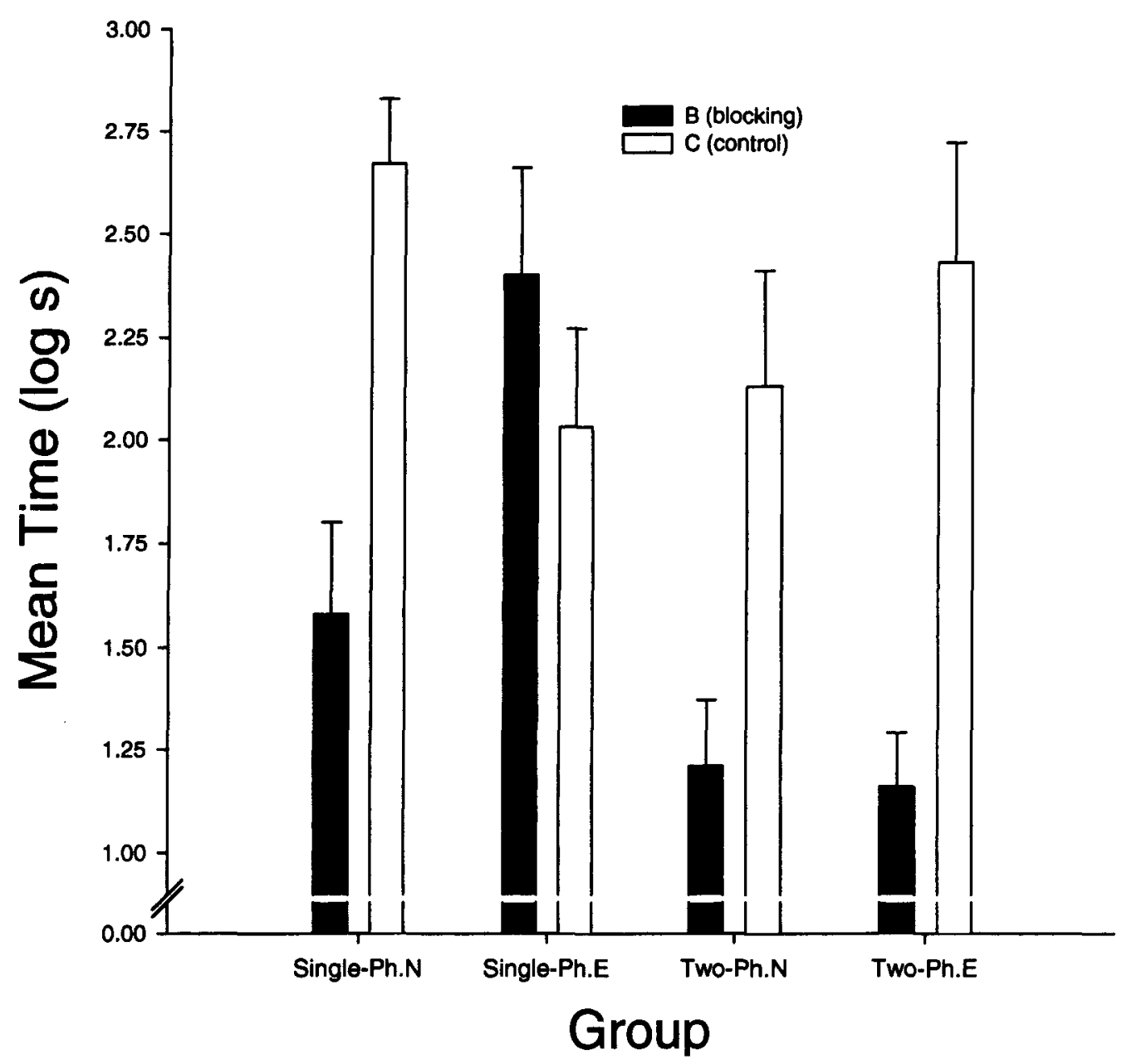

Figure 2. Experiment 2: Mean times to lick for 5 cumulative seconds in the presence of $X$ (the blocked stimulus). Error bars represent standard errors of means.

action between blocking (single-phase vs. two-phase) and treatment (blocking vs. control) $[F(1,40)=5.46, p<$ $.025]$ and a three-way interaction between type of blocking, treatment, and extinction (extinction vs. no extinction) $[F(1,40)=8.17, p<.01]$. All other main effects and interactions were nonsignificant $[F \mathrm{~s}(1,40)=3.06, p \mathrm{~s}>$ $.08]$. Planned comparisons were conducted using the overall error term from the ANOVA. Group Two-Ph B.N showed less suppression of licking than did Group TwoPh C.N $[F(1,40)=8.47, p<.01]$, thereby demonstrating two-phase blocking, and Group Single-Ph B.N suppressed less than did Group Single-Ph C.N $[F(1,40)=$ $11.78, p<.001]$, thereby demonstrating single-phase blocking. Group Single-Ph B.E suppressed more than did Group Single-Ph B.N $[F(1,40)=6.78, p<.05]$, which is indicative of recovery from single-phase blocking. But Group Two-Ph B.E did not differ from Group TwoPh B.N $[F(1,40)<1.0]$, which indicates a failure of 200 $\mathrm{A}-$ trials to achieve recovery from two-phase blocking.
A $2 \times 2 \times 2$ ANOVA conducted on suppression scores to A revealed a main effect for extinction treatment [extinction vs. no extinction; $F(1,40)=33.06, p<.001]$, a two-way interaction between treatment (blocking vs. control) and extinction treatment (extinction vs. no extinction; $F(1,40)=6.22, p<.02]$, and a three-way interaction between all factors $[F(1,40)=4.32, p<.05]$. All other main effects and interactions were nonsignificant $(p s>.05)$. As is evident in Figure 3, the extinction treatment reduced suppression to A. Figure 3 also shows that in the no-extinction condition (N), suppression of licking in response to the A stimulus by the control groups (Groups Single-Ph C.N and Two-Ph C.N) was lower than that of the experimental groups (Groups Single-Ph B.N and Two-Ph B.N, respectively). This difference was significant only in the two-phase condition $[F(1,40)=$ $9.51, p<.01]$ and was likely due either to A's being less salient than $\mathrm{X}$ (e.g., $6 \mathrm{~dB}[\mathrm{C}]$ vs. $8 \mathrm{~dB}[\mathrm{C}]$ above background, respectively), allowing $X$ to partially overshadow 


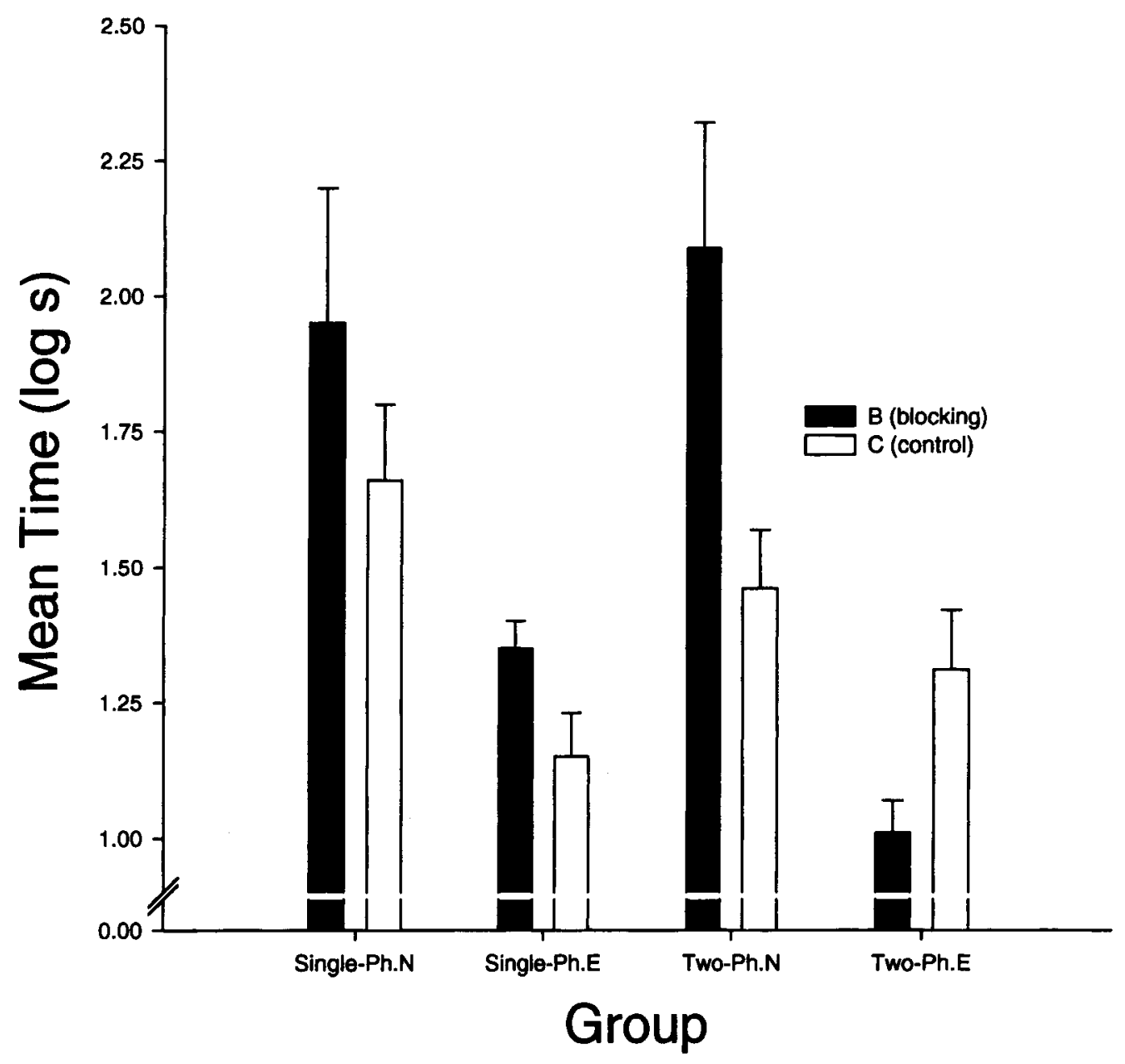

Figure 3. Experiment 2: Mean times to lick for 5 cumulative seconds in the presence of $A$ (the blocking stimulus). Error bars represent standard errors of means.

A in Condition $\mathrm{C}$, or to the fact that A received less training in the control groups than in the blocking groups.

The observation that, after posttraining extinction, the 200 A trials recovered responding to $X$ after single-phase blocking but not after two-phase blocking suggests that the primary problem in recovering responding after twophase blocking (relative to overshadowing and the relative validity effect) is not the occurrence of $A$ alone paired with the US, but the fact that all of the AX-US trials occurred after all of the A-US trials. That is, in the case of single-phase blocking, $X$ probably accrues a small amount of behavioral control (biological significance) during the early $\mathrm{AX}$-US pairings that are presented before the occurrence of many A-US pairings. In the case of twophase blocking, there are no AX-US pairings prior to the completion of all of the A-US pairings. Thus, $X$ never has the opportunity to acquire any behavior control before sufficient A-US pairings have occurred to effect blocking. Furthermore, recovery from single-phase blocking with $200 \mathrm{~A}$ - trials leads us to skepticism concerning the 50:1 ratio rule of training to extinction as being the source of previous failures to achieve recovery from blocking. This rule fails with single-phase blocking in which 200 extinction of $A$ trials reversed blocking when 4 AX-US trials were interspersed with 12 A-US trials. Thus, to explain the ease of reversing single-phase blocking relative to two-phase blocking, we appeal to the concept of biological significance as discussed in the introduction to Experiment 2.

\section{EXPERIMENT 3}

Having demonstrated recovery from single-phase blocking but not recovery from two-phase blocking in Experiment 2 with 200 posttraining A - trials, in Experiment 3 we attempted to produce recovery from two-phase blocking by administering even more extinction trials of Stimulus A than were given in Experiment 2. Blaisdell, Savastano, and Miller (1998) have shown that truly massive extinction is necessary to extinguish a stimulus's biological significance as evidenced by its potential to act as an effective comparator stimulus. Given the relative 
ease with which single-phase blocking was reversed in Experiment 2, past failures to recover responding to a two-phase blocked stimulus by posttraining extinction of the blocking stimulus may have been due to a strong AUS association's having been established prior to the first AX-US pairing. The biological significance of $A$ is likely greater at the time of the first AX-US pairing in two-phase blocking treatment than in single-phase blocking, overshadowing, or the relative validity procedure. At the very least, it is reasonable to expect, all other things being equal, that the number of extinction trials required to recover responding to the target CS should be positively correlated with the amount of reinforced training with the blocking $\mathrm{CS}$, which is a relaxed version of the 50-to- 1 ratio rule discussed above. Therefore, in Experiment 3 , we gave $800 \mathrm{~A}$ - trials in an attempt to obtain recovery from two-phase blocking.

\section{Method}

\section{Subjects and Apparatus}

Twenty-four male (300-405 g) and 24 female (200-305 g) Sprague-Dawley-descended rats, bred in our colony from Holtzman stock, served as subjects. Animals were randomly assigned to one of four groups $(n s=12)$. The animals were housed and maintained as in Experiments 1 and 2. The apparatus and stimuli were identical to those used in Experiment 2.

\section{Procedure}

The critical aspects of Experiment 3 are depicted in Table 3.

Acclimation and blocking treatments for all subjects were identical to those received in the two-phase condition in Experiments 1 and 2. Subjects in the blocking experimental groups (Group Two$\mathrm{Ph}$ B.N and Two-Ph B.E) received four A-US trials per day for 3 days. Subjects in the blocking control groups (Groups Two$\mathrm{Ph}$ C.N and Two-Ph C.E) received four D-US trials per day for 3 days. Following this procedure, all subjects received 1 day of Phase 2 training in which they received 4 AX-US trials. On Days $6-13$, subjects in the extinction (E) condition (Groups Two-Ph B.E and Two-Ph C.E) received nonreinforced exposure (i.e., extinction) of $\mathrm{A}$ in Context 2 as in Experiment 2, except that $10010-\sec \mathrm{A}-$ trials were administered during each 2 -h session (for a total of 800 $A-$ trials) with an intertrial interval of $I \pm 0.5 \mathrm{~min}$. Subjects in the no-extinction condition (Groups Two-Ph B.N and Two-Ph C.N) received equivalent handling and exposure to Context 2 with no nominal stimulus presentations. Subsequently, all animals were reacclimated and tested on $\mathrm{X}$ and $\mathrm{A}$ as in Experiment 2. Two animals (one each from Groups Two-Ph B.N and Two-Ph B.E) took longer than $60 \mathrm{sec}$ to complete the first 5 cumulative seconds of drinking on the

Table 3 Design: Experiment 3

\begin{tabular}{|c|c|c|c|c|}
\hline Group & $\begin{array}{c}\text { Phase 1 } \\
\text { Conditioning }\end{array}$ & $\begin{array}{c}\text { Phase } 2 \\
\text { Conditioning }\end{array}$ & $\begin{array}{l}\text { Phase } 3 \\
\text { Extinction }\end{array}$ & Test \\
\hline Two-Ph B.N & $12 \mathrm{~A}+$ & $4 \mathrm{AX}+$ & context only & $\mathrm{X}, \mathrm{A}$ \\
\hline Two-Ph C.N & $12 \mathrm{D}+$ & $4 \mathrm{AX}+$ & context only & $X, A$ \\
\hline Two-Ph B.E & $12 \mathrm{~A}^{+}$ & $4 \mathrm{AX}+$ & $800 \mathrm{~A}-$ & $\mathrm{X}, \mathrm{A}$ \\
\hline Two-Ph C.E & $12 \mathrm{D}+$ & $4 \mathrm{AX}+$ & $800 \mathrm{~A}-$ & $\mathrm{X}, \mathrm{A}$ \\
\hline
\end{tabular}

Note $-\mathrm{B}=$ blocking treatment $\mathrm{C}=$ control for blocking; $\mathrm{E}=$ extinction treatment; $\mathrm{N}=$ no extinction; $\mathrm{A}$ and $\mathrm{D}$ were a tone or a white noise, counterbalanced within groups; $X$ was a click train; + represents the footshock US; - represents the absence of footshock. Numbers indicate the total number of each type of trial. first day of testing, and their data were therefore eliminated from all analyses.

\section{Results and Discussion}

The basic two-phase blocking effect of Experiments 1 and 2 was successfully replicated. Massive posttraining extinction of the blocking stimulus resulted in conditioned suppression of licking in response to $\mathrm{X}$. These outcomes are illustrated in Figure 4.

A two-way ANOVA conducted on suppression scores to $\mathrm{X}$ with Phase 1 treatment (blocking vs. control) and extinction treatment ( $\mathrm{E}$ or $\mathrm{N})$ as factors revealed a main effect of Phase 1 training $[F(1,42)=19.90, p<.001]$, extinction treatment $[F(1,42)=6.36, p<.02]$, and an interaction between these factors $[F(1,42)=4.51, p<$ $.05]$. Planned comparisons were conducted using the overall error term from the analysis. Group Two-Ph B.N suppressed less than did Group Two-Ph C.N $[F(1,42)=$ $21.69, p<.001]$, thereby demonstrating two-phase blocking, whereas Group Two-Ph B.E suppressed more than did Group Two-Ph B.N $[F(1,42)=10.79, p<.005]$, thereby demonstrating recovery from two-phase blocking as a result of the extinction of $A$.

A similar ANOVA conducted on suppression scores to A revealed a main effect of Phase 1 training $[F(1,42)=$ $7.16, p<.02]$ and extinction treatment $[F(1,42)=61.15$, $p<.001]$ but no interaction was observed $(F<1.0)$.

\section{EXPERIMENT 4}

We have shown that massive extinction of the blocking stimulus (i.e., $200 \mathrm{~A}$ - trials) can produce recovery from single-phase blocking (Experiment 2) and that even more massive extinction of the blocking stimulus (i.e., $800 \mathrm{~A}-$ trials) can produce recovery from two-phase blocking (Experiment 3). However, neither of these demonstrations showed that strong responding to the blocked stimulus depended uniquely on extinction of the blocking stimulus with which that blocked stimulus was trained. Perhaps extinction of any blocking stimulus would recover responding to the blocked stimulus, independent of whether or not the devalued blocking stimulus was the one trained in compound with the blocked stimulus. The purpose of Experiment 4 was to examine stimulus specificity of the present recovery from the blocking effect which, if successfully demonstrated, would rule out nonassociative explanations of the recovery effect. Specifically, rats received training with two independent blocking manipulations, one in which A blocked X (as in Experiments 1-3) and another in which D blocked Y. For one group of rats, both blocking manipulations used the single-phase procedure; for the other group, both blocking manipulations used the two-phase procedure. Then both groups received extinction of $\mathrm{A}$ $(200 \mathrm{~A}-$ trials for the single-phase group and $800 \mathrm{~A}-$ trials for the two-phase group) followed by tests for conditioned suppression to each of the blocked stimuli ( $X$ 


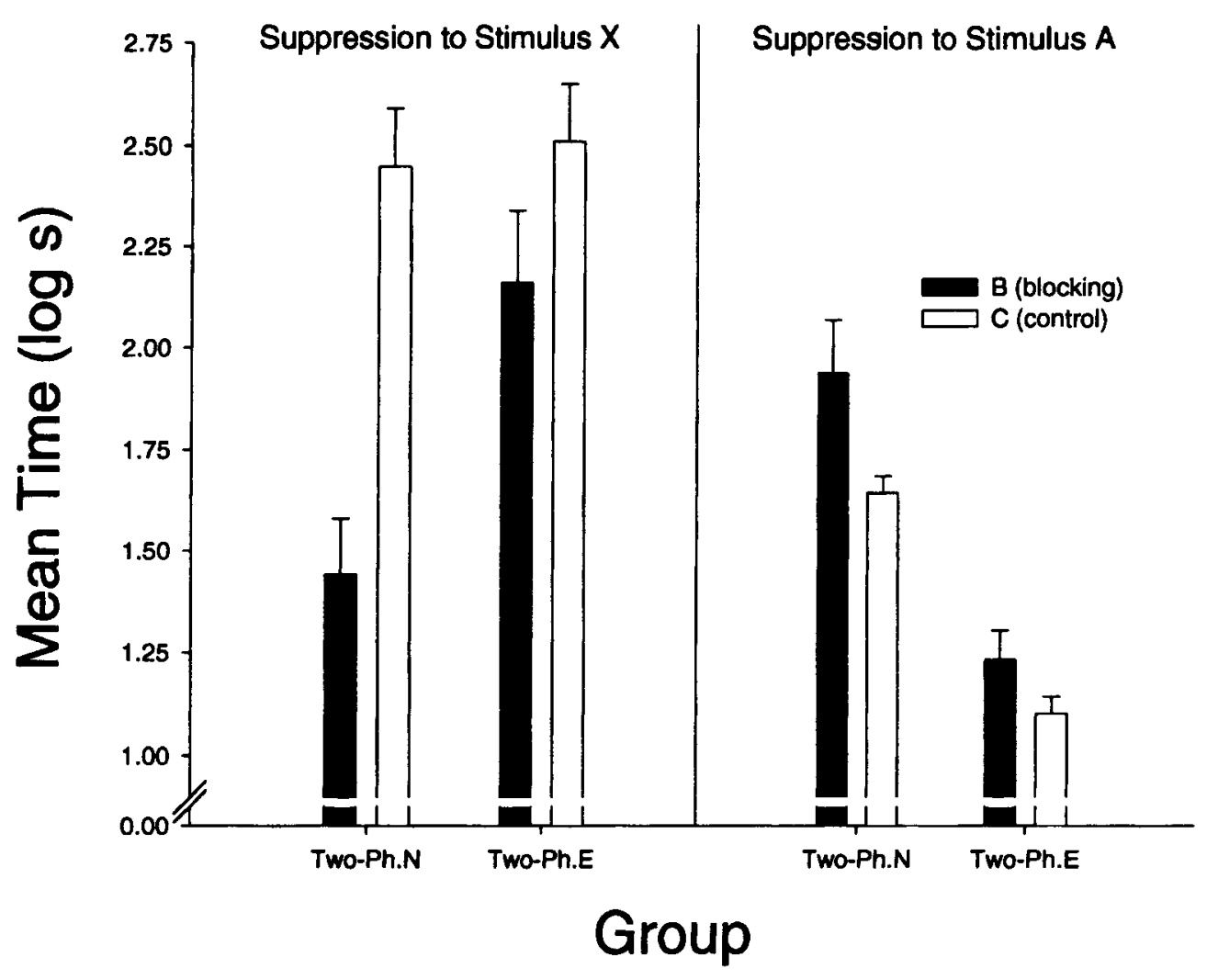

Figure 4. Experiment 3: Mean times to lick for 5 cumulative seconds in the presence of $X$ (the blocked stimulus) and $A$ (the blocking stimulus). Error bars represent standard errors of means.

and $\mathrm{Y}$ ). If the recovery from the blocking effect is dependent on extinction of the same blocking stimulus as was used during training, then strong conditioned suppression (i.e., recovery from blocking) would be expected to $\mathrm{X}$ but not to $\mathrm{Y}$ (i.e., $\mathrm{Y}$ should still be blocked).

\section{Method}

\section{Subjects and Apparatus}

Twenty-four male $(280-470 \mathrm{~g})$ and 24 female $(190-275 \mathrm{~g})$ Sprague-Dawley rats, bred in our colony from Holtzman stock, served as subjects. The animals were randomly assigned to one of two groups ( $n s=24)$. The animals were housed and maintained as in Experiments 1-3. The apparatus and stimuli were identical to those used in Experiments 1-3, except where indicated. In addition to the three speakers previously mentioned, a fourth speaker mounted inside the chamber was able to deliver a buzzing stimulus $8 \mathrm{~dB}(\mathrm{C})$ above background. The tone and noise served as Stimuli A and D, counterbalanced within group. The click and buzz served as stimuli $\mathrm{X}$ and $\mathrm{Y}$, counterbalanced within groups.

\section{Procedure}

The critical aspects of Experiment 4 are depicted in Table 4. Acclimation and blocking treatments for the single-phase and twophase conditions of Experiment 4 were identical to those received by the single-phase and two-phase conditions, respectively, of Experiments $1-3$ except for the addition of the D-US and DY-US trials, which were identical to the A-US and AX-US trials except for the physical identity of the cues. Thus, eight trials were given during each 60 -min conditioning session. Group Single-Phase received three A-US trials, three D-US trials, one AX-US trial, and one DY-US trial per day. On Day 2 (the first day of training), these trials were distributed according to the following pattern: A-US, D-US, A-US, D-US, AX-US, DY-US, A-US, D-US. On Days 3-5, these trials were distributed as follows: A-US, D-US, AX-US, DY-US, A-US, D-US, A-US, D-US. Group Two-Phase received four A-US trials interspersed with four D-US trials per day on Days 2-4. On Day 5, subjects received 4 AX-US interspersed with 4 DY-US trials.

Extinction. On Days 6-13, subjects in the Group Single-Phase received $25 \mathrm{~A}$ - trials per daily 2 -h session as in Experiment 2, for a total of 200 extinction-of-A trials. Group Two-Phase received 100 A - trials per daily 2-h session as in Experiment 3, for a total of 800 extinction-of-A trials.

Reacclimation. On Days 14 and 15, the subjects were given access to the lick tubes in Context 2 during daily 1 -h sessions, which served to restabilize baseline levels of drinking. There were no nominal stimulus presentations during these sessions.

Table 4

Design: Experiment 4

\begin{tabular}{lccr}
\hline Group & $\begin{array}{c}\text { Phase 1 } \\
\text { Conditioning }\end{array}$ & $\begin{array}{c}\text { Phase 2 } \\
\text { Extinction }\end{array}$ & Test \\
\hline Single-Ph & $12 \mathrm{~A}+/ 4 \mathrm{AX}+/ 12 \mathrm{D}+/ 4 \mathrm{DY}+$ & $200 \mathrm{~A}-$ & $\mathrm{X}, \mathrm{Y}$ \\
Two- $\mathrm{Ph}$ & $12 \mathrm{~A}+/ 12 \mathrm{D}+$, then $4 \mathrm{AX}+/ 4 \mathrm{DY}+$ & $800 \mathrm{~A}-$ & $\mathrm{X} . \mathrm{Y}$ \\
\hline
\end{tabular}

Note- $A$ and $D$ were a tone or a white noise, counterbalanced within groups; $\mathrm{X}$ and $\mathrm{Y}$ were a click train and buzz, counterbalanced within groups; + represents the footshock US; - represents the absence of footshock. The slash (/) indicates that treatments on either side of the slash were interspersed. Numbers indicate the total number of each type of trial. 


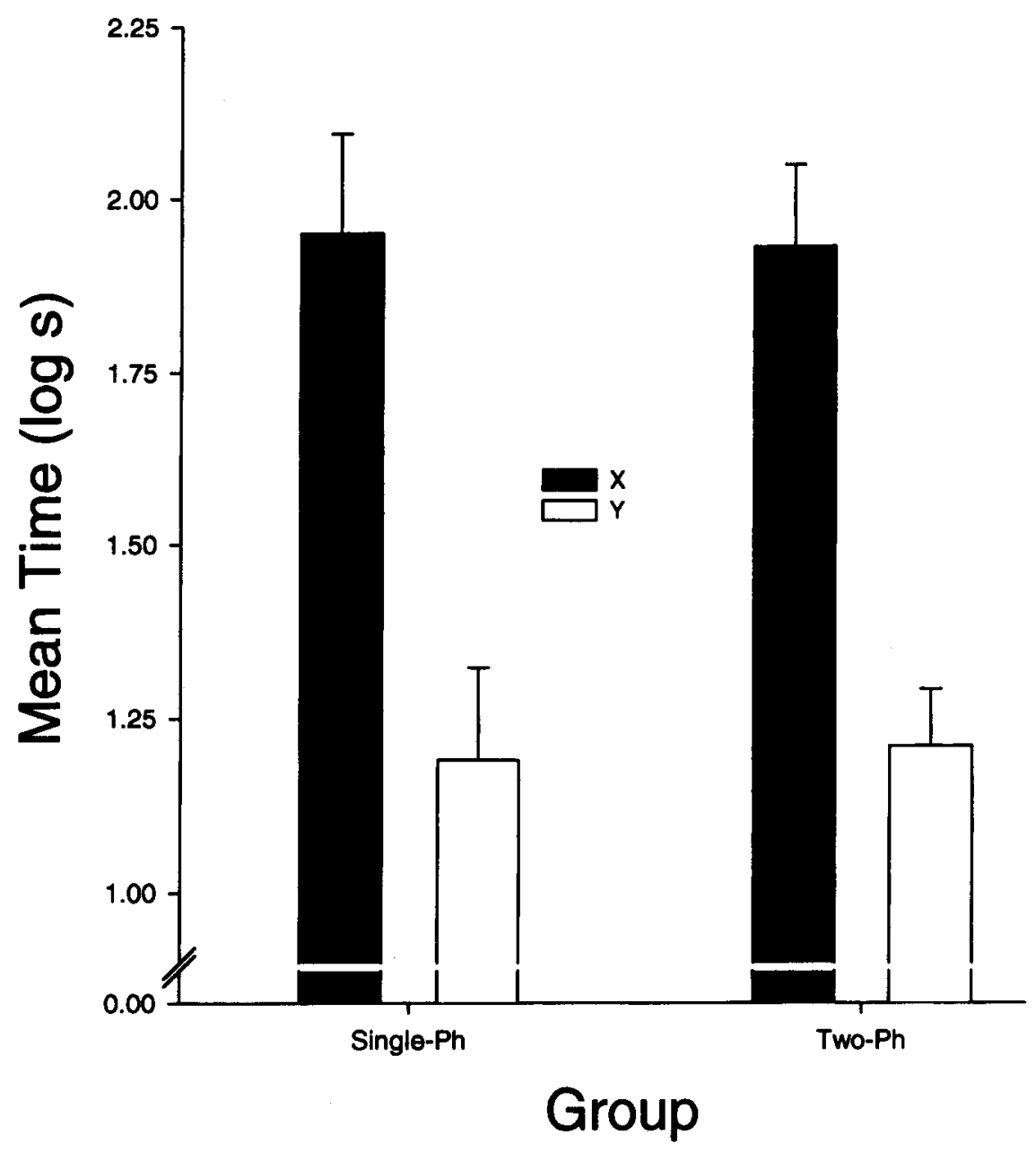

Figure 5. Experiment 4: Mean times to lick for 5 cumulative seconds in the presence of $X$ and Y. Error bars represent standard errors of means.

Testing. On Day 16, half of the subjects from each group were tested for conditioned lick suppression in response to Stimulus $\mathrm{X}$ as in Experiments 1-3, except that Stimulus X remained on for an entire 15-min session in Context 2. The rest of the subjects were tested in a similar fashion on Stimulus $Y$. Maintaining $X$ and $Y$ for a uniform 15 min ensured that data collected on Day 17 were not differentially influenced by differing treatment on Day 16. On Day 17, subjects that had been tested on Stimulus X on Day 16 were tested for suppression to Stimulus Y, using the same test procedure as before. Similarly, subjects that had been tested on Y on Day 16 were tested on $X$ on Day 17. No animal took longer than $60 \mathrm{sec}$ to complete the first 5 cumulative seconds of drinking (i.e., prior to onset of the test stimulus) on either test day.

\section{Results and Discussion}

The single-phase blocking effects of Experiments 1 and 2 and the two-phase blocking effects of Experiments 1-3 were successfully replicated, as seen in suppression to Y. Posttraining extinction of the blocking stimulus (A) resulted in recovery of conditioned suppression to $\mathrm{X}$ but not $\mathrm{Y}$ with both single-phase and two-phase blocking procedures. These outcomes are illustrated in Figure 5.
A $2 \times 2$ ANOVA (Stimulus X vs. Y; Test Day 1 vs. 2) found a large main effect of stimulus $[F(1,92)=93.78$, $p<.0001]$ and a small main effect of test day $[F(1,92)=$ $4.68, p<.05]$, but importantly no interaction between factors $(F<1.0)$. Although a small main effect of test day on conditioned suppression was found, post hoc comparisons of suppression within stimulus across test days found no pairwise differences (Scheffé test: $p$ s > .25 ); thus, within-group scores were pooled within stimulus across test day. A $2 \times 2$ ANOVA (group: singlephase vs. two-phase; stimulus $X$ vs. $Y$ ) was conducted on the suppression scores to $\mathrm{X}$ and $\mathrm{Y}$. This analysis revealed a main effect of stimulus $[F(1,92)=89.63, p<$ $.0001]$, no main effect of group $(F<1.0)$, and no interaction between factors $(F<1.0)$. Planned comparisons using the overall error term from the latter ANOVA found greater suppression to $\mathrm{X}$ than to $\mathrm{Y}$ in both groups $[F \mathrm{~s}(1,92)>37.00, p \mathrm{~s}<.0001]$ to be the source of the main effect of stimulus. Thus, extinction of A resulted in strong conditioned suppression to the blocked stimulus with which it was compounded (i.e., X) and not to the blocked 
stimulus which was not compounded with A during blocking treatment (i.e., Y).

Experiment 4 demonstrates that the recovery from both single-phase and two-phase blocking produced by extinction of the blocking stimulus was specific to the particular blocked stimulus that was trained in compound with the extinguished blocking stimulus. This outcome supports the view that the recovery from blocking effects seen in Experiments 2 and 3 resulted from changes in the comparator status of the blocked stimulus's comparator stimulus and not the nonassociative effects of the extinction manipulation.

\section{GENERAL DISCUSSION}

Experiment 1 demonstrated both single-phase and two-phase blocking with the present parameters (provided, in the case of single-phase blocking, that the first trial was an A-US pairing rather than an AX-US pairing). Moreover, A-US trials prior to AX-US trials were necessary for blocking to occur in the single-phase condition. In Experiment 2, we found robust suppression to $\mathrm{X}$ as a result of 200 posttraining extinction trials with $\mathrm{A}$ after single-phase but not two-phase blocking. Experiment 3 resulted in strong suppression to $X$ after twophase blocking as a consequence of the administration of 800 posttraining $\mathrm{A}-$ trials. These results suggest that blocking is due, at least in part, to an expression deficit, thereby placing it within the same realm as other cuecompetition effects (e.g., overshadowing, relative validity, and US-preexposure effects) which have previously been found to be reversible without further training with the target stimulus. Finally, Experiment 4 demonstrated that recovery from blocking was specific to the blocked stimulus trained in compound with the extinguished stimulus.

Recovery of responding to a target stimulus as a result of extinguishing its competing stimulus has been viewed as evidence for associative retrospective revaluation. Retrospective revaluation is the processing of information concerning a previously trained stimulus on a trial during which that stimulus is absent. The associative retrospective revaluation of stimuli has been observed in humans making causal judgments (which, in many respects, appears to obey the rules of Pavlovian conditioning: e.g., Chapman, 1991; Dickinson \& Burke, 1996; Shanks, 1985; Van Hamme, 1994; Williams, Sagness, \& $\mathrm{McPhee}, 1994$ ) as a result of posttraining extinction (deflation) and inflation of competing causes, and in animal Pavlovian conditioning as a result of posttraining extinction (deflation) of competing stimuli (Barnet et al., 1993; Cole et al., 1995; Kaufman \& Bolles, 1981; Matzel, Brown, \& Miller, 1987; Matzel et al., 1985; Matzel, Shuster, \& Miller, 1987) and, under select conditions, as a result of posttraining inflation of competing stimuli (Denniston et al., 1996; Miller \& Matute, 1996). The occurrence of retrospective revaluation with Pavlovian procedures is contrary to the predictions of the RescorlaWagner (1972) model. In the Rescorla-Wagner model, $\alpha$, the learning rate parameter for a CS, has a nonzero value only when that $C S$ is present on a trial. On trials on which the CS is absent, $\alpha$ for that CS is zero. This leads to a prediction of no change in the associative status of the CS on trials in which that CS is absent, such as during the extinction phases of Experiments 2 and 3. Thus, devaluing the associative status of the blocking CS in the absence of the blocked CS should not alter the associative status of the blocked CS.

Recently, however, Van Hamme and Wasserman (1994) have presented a revision of the Rescorla-Wagner model that allows for changes in a CS's associative strength on trials in which that CS is absent provided that the CS was previously presented. In the Van Hamme and Wasserman model, $\alpha$ takes on a nonzero (albeit negative) value on trials in which the target $\mathrm{CS}(\mathrm{X})$ is absent. For example, during Phase 2 of Experiment 2 (i.e., $\mathrm{A} \rightarrow$ no US), $\alpha_{\mathrm{A}}$ is presumably positive whereas $\alpha_{\mathrm{X}}$ is negative. This leads to the prediction of a decrease in A's associative strength and an increase in X's associative strength. Thus, retrospective revaluation of a CS is predicted by the Van Hamme and Wasserman model. Notably, in the Van Hamme and Wasserman model, retrospective revaluation effects are presumably the result of new learning about the CS (i.e., altered associative strength) on trials in which the CS is absent. This contrasts with the comparator hypothesis (Miller \& Matzel, 1988; Miller \& Schachtman, 1985) in which the altered behavior seen after extinction of the comparator (in this case, blocking) stimulus is viewed as a change in the expression of an acquired association rather than a change in associative status.

The Van Hamme and Wasserman (1994) model and the comparator hypothesis (Miller \& Matzel, 1988; Miller \& Schachtman, 1985) can explain both the present results and previously reported changes in responding to a target $\mathrm{CS}$ as a result of posttraining associative inflation or deflation of a potential competing stimulus. However, there are some phenomena in the literature that are predicted by the comparator hypothesis but are inexplicable in terms of the Van Hamme and Wasserman model. For example, the CS-preexposure effect is inexplicable in terms of either the Van Hamme and Wasserman model or the Rescorla-Wagner (1972) model. However, the comparator hypothesis (along with Wagner's, 1981, SOP model and Dickinson \& Burke's, 1996, modified SOP model) successfully explains the CS-preexposure deficit in terms of CS-preexposure treatment establishing strong CS-context associations (see Grahame, Barnet, Gunther, \& Miller, 1994). Moreover, the comparator hypothesis (but not Wagner's SOP model or Dickinson \& Burke's modified version of SOP) can explain why CS-preexposure treatment and overshadowing treatment counteract each other (Blaisdell, Bristol, Gunther, \& Miller, 1998). That is, preexposing the to-be-overshadowed stimulus $(X)$ prior to overshadowing treatment, in which a more salient stimulus (A) is present during training of the less salient target CS X (i.e., AX $\rightarrow$ US), prevents $A$ from overshadowing $X$. Furthermore, the presence of A during training 
alleviates the reduced responding to $X$ that ordinarily results from CS preexposure. In the framework of the comparator hypothesis, preexposure to $\mathrm{X}$ establishes the context as X's comparator stimulus, whereas overshadowing treatment interferes with the attenuating effects of the context on responding to $X$.

Both single-phase and two-phase blocking procedures yield little responding to $X$. However, only 200 (or less) $A-$ trials were needed to recover responding to $X$ after single-phase blocking, whereas a greater number of $\mathrm{A}-$ trials were required for recovery after otherwise equivalent two-phase blocking. What is the basis of this difference? That is, what is it about cue competition effects resulting from single-phase training that is different from those that result from the two-phase procedure? One possibility that we discussed in the introduction is that, at the time of the first AX-US trial, A has likely already acquired more associative strength in two-phase blocking than in single-phase blocking. With A only moderately excitatory at the time of the first AX-US trial in the single-phase condition, $\mathrm{X}$ begins to acquire biological significance (i.e., behavioral control), and once acquired it is very difficult to lose. In contrast, in the two-phase condition, $\mathrm{A}$ is highly excitatory at the time of the first AX-US trial. Consequently, any association between $\mathrm{X}$ and the US that is acquired is latent; that is, $X$ does not acquire biological significance that protects it from increased blocking. Alternatively stated, the A-US pairings after the first AX-US trial in the singlephase condition do contribute to blocking of $\mathrm{X}$, but they are not as effective as A-US trials that precede all of the $\mathrm{AX}$-US trials. In the single-phase procedure, the first AX-US trial was preceded by only two A-US trials. Consequently, it is likely that $\mathrm{X}$ acquired more biological significance in the single-phase than in the two-phase procedure. Throughout training, $X$ presumably acquired less biological significance on each successive $\mathrm{AX}-\mathrm{US}$ trial due in part to the accumulating A-US pairings. Thus, in single-phase blocking, $X$ probably asymptoted at a moderate level of biological significance (although below the threshold for appreciable suppression). However, in two-phase blocking, the first AX-US trial was preceded by 12 A-US pairings, thereby preventing $\mathrm{X}$ from acquiring as much biological significance as it would in the single-phase condition (due to A's being a better predictor of the US in two-phase than in singlephase blocking at the time of the first AX-US trial). Thus, the lesser biological significance of $X$ at the end of training in the two-phase procedure than in the singlephase procedure can explain why a greater amount of extinction of $\mathrm{A}$ was required to produce recovery from two-phase blocking (i.e., $800 \mathrm{~A}$ - trials) than from singlephase blocking (i.e., $200 \mathrm{~A}-$ trials). Notably, biological significance is an additional concept that must be appended to the comparator mechanism to fully explain the present results. In the framework of the comparator hypothesis, $A$ and $X$ presumably acquire the same absolute associations with the US in both single-phase and two- phase blocking. However, it is the difference in biological significance of $X$ (maximal response potential ever achieved) between these two blocking procedures that we are suggesting results in the differential amounts of extinction necessary to produce the unblocking of $\mathrm{X}$. The comparator hypothesis simply provides the theoretical basis for assuming that a strong $\mathrm{X}$-US association was acquired during training, and that deflation of X's comparator stimulus (A) will result in the expression of the initially latent X-US association. The concept of biological significance providing protection against cue competition and the comparator hypothesis appear necessary to explain the present results. These two principles are not incompatible, but neither does either of these generate the other.

One might ask why so many extinction trials with the comparator stimulus are necessary to induce recovery from cue competition (blocking in the present case). In our early studies of posttraining extinction of comparator stimuli, we were surprised that far more extinction trials were necessary to obtain recovery than were needed to eliminate conditioned responding to the competing CS. However, Yin, Grahame, and Miller (1993) have argued, with supporting data, that this seeming discrepancy arises from stimulus generalization between the comparator stimulus as it is perceived during training and the comparator stimulus as it is perceived during extinction treatment. That is, the absence of the target CS and the US during the comparator stimulus-extinction trials (and subsequent test trials that directly examine the associative status of the comparator stimulus through its own response potential) presumably constitute a significant change in context from the conditions under which the comparator stimulus (and target $\mathrm{CS}$ ) was trained. Consistent with this view, Yin et al. found that far fewer nonreinforced presentations of the comparator stimulus were necessary to obtain a comparator deflation effect when the nonreinforced presentations of the comparator stimulus were intermingled with the target CS training trials than when they all followed the target CS training trials. Notably, Yin et al. used the same context for target CS training and for extinction of the comparator stimulus. Thus, the large number of comparator stimulus-extinction trials required in the present experiment to enhance responding to the target CS when devaluation of the comparator stimulus follows completion of training serves to compensate for the extent to which the effect is weakened by generalization decrement between the comparator stimulus as it is perceived in training and as it is perceived during the posttraining devaluation procedure.

In conclusion, the present demonstration of recovery from both single- and two-phase blocking, in conjunction with prior demonstrations of recovery from cue competition (e.g., Batsell, 1997; Cole et al., 1995; Cole et al., 1996; Cole et al., 1997; Kasprow et al., 1982; Kaufman \& Bolles, 1981; Kraemer et al., 1988; Matzel et al., 1985; Matzel, Shuster, \& Miller, 1987), suggests that all cuecompetition effects have a common basis. 


\section{REFERENCES}

Balaz, M. A., Gutsin, P., Cacheiro, H., \& Miller, R. R. (1982). Blocking as a retrieval failure: Reactivation of associations to a blocked stimulus. Quarterly Journal of Experimental Psychology, 34B, 99-113.

Barnet, R. C., Grahame, N. J., \& Miller, R. R. (1993). Local context and the comparator hypothesis. Animal Learning \& Behavior, 21, 1-13.

BATSELL, W. R. (1997). Retention of context blocking in taste-aversion learning. Physiology \& Behavior, 61, 437-446.

Blaisdell, A. P., Bristol, A. S., Gunther, L. M., \& Miller, R. R. (1998). Overshadowing and latent inhibition counteract each other: Further support for the comparator hypothesis. Journal of Experimental Psychology: Animal Behavior Processes, 24, 335-351.

Blaisdell, A. P., Savastano, H. I., \& Miller, R. R. (1998). Biological significance and cue competition: Contrasting encoding and retrieval models. Manuscript in preparation.

Chapman, G. B. (1991). Trial order affects cue interaction in contingency judgment. Journal of Experimental Psychology: Learning, Memory, \& Cognition, 17, 837-854.

Cole, R. P., Barnet, R. C., \& Miller, R. R. (1995). Effect of relative stimulus validity: Learning or performance deficit? Journal of Experimental Psychology: Animal Behavior Processes, 21, 293-303.

Cole, R. P., Denniston, J. C., \& Miller, R. R. (1996). Reminderinduced attenuation of the effect of relative stimulus validity. Animal Learning \& Behavior, 24, 256-265.

COlE, R. P., Gunther, L. M., \& Miller, R. R. (1997). Spontaneous recovery from the effect of relative stimulus validity. Learning \& $\mathrm{Mo}$ tivation, 28, 1-19.

Denniston, J. C., Miller, R. R., \& Matute, H. (1996). Biological significance as a determinant of cue competition. Psychological Science, 7, 325-331.

Dickinson, A., \& Burke, J. (1996). Within-compound associations mediate the retrospective revaluation of causality judgements. Quarterly Journal of Experimental Psychology, 49B, 60-80.

Dickinson, A., \& Charnock, D. J. (1985). Contingency effects with maintained instrumental reinforcement. Quarterly Journal of Experimental Psychology, 37B, 397-416.

Grahame, N. J., Barnet, R. C., Gunther, L. M., \& Miller, R. R. (1994). Latent inhibition as a performance deficit resulting from CScontext associations. Animal Learning \& Behavior, 22, 395-408.

Gunther, L. M., Denniston, J. C., \& Miller, R. R. (1998). Renewal of comparator stimuli. Learning \& Motivation, 29, 200-219.

KAMIN, L. J. (1968). "Attention-like" processes in classical conditioning. In M. R. Jones (Ed.), Miami Symposium on the Prediction of Behavior: Aversive stimulation (pp. 9-31). Miami: University of Miami Press.

Kasprow, W. J, Cacheiro, H., Balaz, M. A., \& Miller, R. R. (1982). Reminder-induced recovery of associations to an overshadowed stimulus. Learning \& Motivation, 13, 155-166.

Kalfman, M. A., \& Bolles, R. C. (1981). A nonassociative aspect of overshadowing. Bulletin of the Psychonomic Society, 18, 318-320.

Kraemer, P. J., Lariviere, N. A., \& SPear, N. E. (1988). Expression of a taste aversion conditioned with an odor-taste compound: Overshadowing is relatively weak in weanlings and decreases over a retention interval in adults. Animal Learning \& Behavior, 16, 164-168.

MaCkintosh, N. J. (1975). A theory of selective attention: Variations in the associability of stimuli with reinforcement. Psychological Review, 82, 276-298.

Matzel, L. D., Brown, A. M., \& Mili.er, R. R. (1987). Associative effects of US preexposure: Modulation of conditioned responding by an excitatory training context. Journal of Experimental Psychology: Animal Behavior Processes, 13, 65-72.

Matzel, L. D., Schachtman, T. R., \& Miller, R. R. (1985). Recovery of an overshadowed association achieved by extinction of the overshadowing stimulus. Learning \& Motivation, 16, 398-412.
Matzel, L. D., Shuster, K., \& Miller, R. R. (1987). Covariation in conditioned response strength between stimuli trained in compound. Animal Learning \& Behavior, 15, 439-447.

Miller, R. R., Barnet, R. C., \& Grahame, N. J. (1992). Responding to a conditioned stimulus depends on the current associative status of other cues present during training of that specific stimulus. Journal of Experimental Psychology: Animal Behavior Processes, 18, 251-264.

Miller, R. R., \& MATUTE, H. (1996). Biological significance in forward and backward blocking: Resolution of a discrepancy between animal conditioning and human causal judgment. Journal of Experimental Psychology: General, 125, 370-386.

MilleR, R. R., \& MATZEL, L. D. (1988). The comparator hypothesis: A response rule for the expression of associations. In G. H. Bower (Ed.), The psychology of learning and motivation (Vol. 22, pp. 5192). San Diego: Academic Press.

Miller, R. R., \& Schachrman, T. R. (1985). Conditioning context as an associative baseline: Implications for response generation and the nature of conditioned inhibition. In R. R. Miller \& N. E. Spear (Eds.), Information processing in animals: Conditioned inhibition (pp. 5188). Hillsdale, NJ: Erlbaum.

Miller, R. R., Schachtman, T. R., \& Matzel, L. D. (1988). [Failure to attenuate blocking by posttraining extinction of a blocking stimulus.] Unpublished raw data.

Pavlov, I. J. (1927). Conditioned reflexes (G. V. Anrep, Trans.). London: Oxford University Press.

PeARCE, J. M. (1987). A model for stimulus generalization in Pavlovian conditioning. Psychological Review, 94, 61-73.

Pearce, J. M., \& Hall, G. (1980). A model for Pavlovian conditioning: Variations in the effectiveness of conditioned but not unconditioned stimuli. Psychological Review, 87, 332-352.

RESCORLA, R. A., \& WAGNER, A. R. (1972). A theory of Pavlovian conditioning: Variations in the effectiveness of reinforcement and nonreinforcement. In A. H. Black \& W. F. Prokasy (Eds.), Classical conditioning II: Current research and theory (pp. 64-99). New York: Appleton-Century-Crofts.

Schachtman, T. R., Gee, J. L., Kasprow, W. J., \& Miller, R. R. (1983). Reminder-induced recovery from blocking as a function of the number of compound trials. Learning \& Motivation, 14, 154-164.

SHANKS, D. R. (1985). Forward and backward blocking in human contingency judgement. In G. H. Bower (Ed.), The psychology of learning and motivation (Vol. 21, pp. 229-261). San Diego: Academic Press.

VAN Hamme, L. J. (1994). Associative and statistical accounts of cue competition in causality judgements. Unpublished doctoral dissertation, University of Iowa, lowa City.

Van Hamme, L. J., \& Wasserman, E. A. (1994). Cue competition in causality judgements: The role of nonpresentation of compound stimulus elements. Learning \& Motivation, 25, 127-151.

WAGNER, A. R. (1981). SOP: A model of automatic memory processing in animal behavior. In N. E. Spear \& R. R. Miller (Eds.), Information processing in animals: Memory mechanisms (pp. 5-47). Hillsdale, NJ: Erlbaum.

Williams, D. A., \& Docking, G. L. (1995). Associative and normative accounts of negative transfer. Quarterly Journal of Experimental Psychology: Human Experimental Psychology, 48A, 976-998.

Williams, D. A., Sagness, K. E., \& McPheE, J. E. (1994). Configural and elemental strategies in predictive learning. Journal of Experimental Psychology: Learning, Memory, \& Cognition, 20, 694-709.

Yin, H., Grahame, N. J., \& Miller, R. R. (1993). Extinction of comparator stimuli during and after acquisition: Differential facilitative effects on Pavlovian responding. Learning \& Motivation, 24, 219-241.

(Manuscript received May 10, 1998; accepted for publication July 1, 1998.) 